\title{
Determination of set potential voltages for cucumber mosaic virus detection using screen printed carbon electrode
}

\begin{abstract}
Cucumber Mosaic Virus (CMV) is a most dangerous pathogen among the cucurbit plant which it striking cucumbers, zucchinis, squashes, watermelons but it also striking to noncucurbit such as peppers, tobaccos, celeries, beans and tomatoes. Symptoms shown by this virus when they starting to strike are very significant and at the end can kill the hosts they infected. In order to detect these viruses, biosensor such as screen-printed carbon electrode (SPCE) is developed and fixes a set potential voltage is defined using Chronoamperometry (CM) immunosensor technique. For short introduction, CM is a process which is a constant applied potential voltage between the working and reference electrode is maintained in order to create an electrons transfer for the oxidation or reduction species taking place at the surface of working electrode is measured and in this manuscript, complete details about measurement were used to finding the stable set potential voltages will be pointed out.
\end{abstract}

Keyword: Cucumber mosaic virus; Screen printed carbon electrode; Immunosensor 